\title{
Effectiveness of Macedonian Tourism Marketing Policy on Visitors at Tourism Fairs
}

\author{
Dejan Galovski \\ Sofia University St. Kliment Ohridski, Faculty of Economics \\ and Business Administration, Bulgaria \\ dejangalovski@gmail.com
}

In this paper, the efforts that Macedonia makes for promotion and positioning it as a tourist destination will be reviewed. In recent years Macedonia much effort has invested in the development and promotion of tourism products, as well strategies, plans, and programs to promote that nation's tourism potential. The Agency for the Promotion and Support of Tourism has a major role through their annual programs realize goals and projects to promote and support tourism. Every year, the agency participates in international tourism fairs where it promotes the tourism potentials and natural beauties of Macedonia, and establishes collaboration contacts for the development of tourism there. In addition to international tourism fairs, they participate in creating marketing campaigns, promotional videos, online campaigns, and similar activities. In this paper, national marketing campaigns as a tourist destination, which have primary role of promoting Macedonia in global media, will be analysed and their effects reviewed. For the purpose of this paper, research has been conducted, a questionnaire with multiple choice, checkbox, and scale questions about visitors' opinions at the international tourism fairs in Sofia, Bulgaria, and in Belgrade, Serbia in February 2016. Interviewees were specifically asked about whether they were familiar with the range of tourism services and facilities in Macedonia, tourism marketing campaigns of Macedonia, the latter's impact on them, and the evaluation of the presentation of Macedonia at the tourism fair. The results have shown that visitors have a positive assessment of the presentation of Macedonia at the tourism fair, and most of them often watch television and Internet advertisements for Macedonia as a tourist destination. Furthermore, at the tourism fair in Sofia, using an open questionnaire, a representative of the Agency for the Promotion and Support of Tourism was interviewed about the participation of Macedonia at the international fairs and their experiences and expectations.

Keywords: tourism, tourism fair, marketing, promotion, Macedonia https://doi.org/10.26493/2335-4194.10.83-89

\section{Introduction}

One of the oldest market institutions, maintaining its vitality from the Middle Ages until today, is fairs. They first developed as sales sites and later evolved into exhibitions of products. The fairs are a strong impetus to trade and one of the attributes of a market economy. Tourism fairs are an effective tool of marketing tourism. At a tourism fair, visitors can be directly introduced to the tourist services of companies. In this paper, research will be conducted about visitors' opin- 
ions at tourism fairs about tourist services, and the marketing of one tourist destination and its influence on visitors.

\section{Methodology}

In this research, primary data obtained from questionnaires and interviews conducted by the researcher will be used, accompanied by secondary data from published books and Internet sources regarding tourism fairs and the national tourism marketing of Macedonia. The questionnaire contains multiple-choice, scale, and dichotomous questions. The form of the questionnaire was interviewer-completion.

A structured interview was conducted with a representative from the Agency for the Promotion and Support of Tourism from Macedonia at the international tourism fair in Sofia, Bulgaria about tourism services and the promotion of Macedonia and experiences from international tourism fairs.

\section{Hypotheses}

In this research two hypotheses will be tested:

$\mathrm{H} 1$ The majority of respondents saw advertising about Macedonia as a tourist destination on the internet.

$\mathrm{H} 2$ The majority of respondents know that lake tourism is offered in Macedonia, and the first synonym of Macedonia as a tourist destination is Lake Ohrid.

\section{Importance of Tourism Trade Fairs}

It was in the late 1950 s that the first serious attempts were made to establish and organize tourism fairs. The main objective of the tourist industry was two-fold from the very beginning (Bhatia, 2007, p. 287):

1. As 'public fairs' the purpose is to enable travel agents and tour operators, hoteliers, carriers and National Tourist Officers to establish contact with the travelling public, and thus to promote their programs and services.

2. As 'trade fairs' in the more specific sense, their aim is to create opportunities for contact and business discussion, contract negotiations and exchange information within the industry itself.
Trade fair tourism involves an exhibition organized so that companies in a specific industry can showcase and demonstrate their latest products, services, study the activities of rivals, and examine recent market trends and opportunities (Esombia, 2013, p.23)

The first such travel trade fair, known as the International Tourism Borse (Іт B), was held in 1967 in Berlin. Since then, there have been a number of other countries that have organized travel trade fairs regularly. The enthusiastic participation in these fairs is a result of the ever-expanding travel trade industry. A large number of exhibitors participate in these fairs, representing all segments of the travel industry, including travel agents, tour operators, hoteliers, airline companies, shipping companies, national tourist organizations, etc. In addition, travel trade media is present (Bhatia, 2007, p. 287).

Participation in travel trade fairs has several inherent advantages, which are responsible for the growth in their numbers over the years as wells as the participation. Some of these advantages of participating in the travel trade fairs are as follow (Bhatia, 2007, p. 288):

- Opportunity for both buyers and sellers of tourism services to meet under one roof and transact business;

- Lower cost of participation because of the advantage of scale;

- Effective vehicle of communication with clients;

- Better quality of attendance;

- Single platform to introduce the product (in the form of a brochure);

- Easy access to travel trade media;

- Cultivating new information about the travel product;

- Acquiring new information about the travel product;

- Opportunity for effective public relations.

Trade fairs make it easy for companies to evaluate their competitors. Exchanging information and holding talks remains important. In a decision-making situation the degree of personal trust established between business partners is a key factor. In the competition for a business partner's trust personal acquain- 
Table 1 Assets Aimed for Realization of the Program for Promotion and Support of Tourism

\begin{tabular}{lrrrrrr}
\hline Category & 2010 & 2011 & 2012 & 2013 & 2014 & 2015 \\
\hline Total asset & $9,327,000$ & $7,600,000$ & $8,047,000$ & $139,935,000$ & $231,380,000$ & $22,720,000$ \\
Assets for tourism fairs & $3,727,000$ & $3,500,000$ & $4,116,060$ & - & $18,870,000$ & - \\
\hline
\end{tabular}

Notes Based on data from www.tourismmacedonia.gov.mk, in MKD $(1 \mathrm{MKD}=0.01612 €)$.

tance and word-of-mouth marketing become values in their own right. Whether at home or abroad, the ability to maintain close customer contact is an essential factor in the quest for strategic success.

It is important that tourism firms attend such trade fairs, be they national, regional or international; with minimum cost for participation, maximum advantage is obtained via the introduction and promotion of their product to make business contacts and contracts.

Tourism trade fairs are organized annually and often are combined with trade fairs for sports equipment, wine and food, education and other compatible fields. The two most important and prestigious international tourism trade fairs are the World Trade Mart ( $\mathrm{w}$ T M) in London, $\mathrm{UK}$ and the International Tourism Borse (г т в) in Berlin, Germany; the interest and attendance on these fairs are at an extremely high level.

\section{Macedonian National Marketing Tourism Policy}

In conducting and creating the national marketing tourism policy in Macedonia, the main role is played by the Tourism sector of the Ministry of Economy and the Agency for the Promotion and Support of Tourism, which was established on o1 December 2008.

Since 2010, assets from the budget of Republic of Macedonia have been allocated to the agency for the realization of the program for promotion and support of tourism; total assets for each year can be seen in Table 1.

Promotion of Macedonian tourism potential at international tourism fairs from 2010 to 2015 :

- 2010 - Belgrade, Berlin, Istanbul, Ljubljana, Pristina, Sarajevo, Moscow

- 2011 - Belgrade, Berlin, Istanbul, Utrecht, Helsinki, Ljubljana, Tel Aviv, Pristina

- 2012 - Belgrade, Berlin, Istanbul, Utrecht, Helsinki, Essen, Izmir, London

- 2013 - Belgrade, Berlin, Istanbul, Utrecht, Helsin- ki, Moscow, Vienna, Warsaw, Brussels, Milan, Sofia, Goteborg, Tirana, Poznan, Shanghai, Tokyo, India, Florida (USA)

- 2014 - Belgrade, Berlin, Istanbul, Utrecht, Helsinki, Moscow, Vienna, Brussels, Milan, Sofia, Goteborg, Poznan, Izmir, Tokyo, London

- 2015 - Belgrade, Berlin, Istanbul, Utrecht, Helsinki, Moscow, Brussels, Sofia, Goteborg, Tokyo, London, Paris, Cologne, Rimini, Madrid

Assets aimed for the realization of the program for promotion and support are allocated for following activities: conventional promotional activities (making and printing promotional material, presentation at international fairs, inviting international tour operators and journalists, billboard campaign, promotion in international print media, promotion of tourist potential and education through international matches, conferences, workshops with international meaning), activities for electronic promotion, organizing Days of Macedonian tourism in particular countries, specific promotion activity aimed to transit passengers, activities for tourism support, subsidiary of foreign organized tourist turnover and many other activities.

The most important national branding campaigns are 'Macedonia Timeless' and 'Essential Macedonia;' the Internet and Google is equally important for the promotion of the tourist destination in the new era of digital technologies.

Macedonia Timeless is a series of promotional tourist videos about the Republic of Macedonia. The videos showcase scenery from the Balkan country and of Macedonian culture to a foreign audience. Each video of the project is the work of a private production company, carried out on behalf of the Macedonian government, which officially funds the effort. The defined purpose of the project is 'to promote awareness of Macedonian tourism opportunities' ('Macedonia Timeless,' 2017). 
The first group of tourism commercials consists of:

- 2 general commercials

- Macedonian Temples

- Ohrid ... City of Light

- Macedonian Wines

- Archaeology

Following these, a few more commercial videos for the capital city Skopje, Macedonian Food, Adventure in Macedonia and Macedonia for couples were made.

The website of Macedonia Timeless campaign is useful for potential tourists, as it offers basic information about Macedonia and a large amount of useful information for tourists to plan their trip. There is a 'Things To Do' section with activities, attractions, and tours, as well as online brochures.

Also from campaign Macedonia Timeless are six thematic brochures: Sound (Tradition and Events), Touch (Archaeology, History, and Culture), Taste (Wine and Food), Instinct (Hunting and Fishing), Scent (Rural Beauty), and Sight (Nature and Adventure).

From 27 June 2012 to date, there have been more than $10,800,000$ views on the official YouTube channel of Macedonia Timeless. More than 40.000 people have clicked 'Like' on the official Facebook page of Macedonia Timeless.

Essential Macedonia is a documentary about Macedonia's tourist potentials and natural resources, depicting the country's essence by presenting its natural, historical, and cultural treasury and images of the everyday life of its citizens, produced by 'Travel Channel International.'

This documentary was broadcasted on 8 March 2011 on the Travel Channel in a duration of 30 minutes. The documentary has been presented in 20 languages and 120 countries across the globe for three years. Travel Channel International is a world-renowned $\mathrm{TV}$ channel specializing in tourism and promotion of new tourist destinations ('Dokumentaren film za Makedonija,' 2011).

Presenter Danny Robins is enthusiastic about Macedonia's hospitality, delicious food, possibilities for mountain biking, the beauty of Ohrid Lake, wine tourism and dazzling landscapes ('Travel Channel: Macedonia an Exciting Destination,' 2010).
Google promotion aims to promote Macedonia as a tourist destination, increasing visits to the website of macedonia-timeless.com and to a presentation of the possibilities for tourists and increasing total numbers of tourists in Macedonia.

Target countries for 2015 were Serbia, Bulgaria, Turkey, Netherlands, Russia, Italy, France, Great Britain, Germany and Sweden. Criteria for selection of the 10 countries were the number of foreign tourists, direct flights, subsidized countries, tourists who are major consumers, and hits on the website from 2014.

Google Online campaign is realized through:

- Banners and pop ads with videos and pictures

- 257 keywords in 6 languages

- YouTube videos

Through banners and pop ads interest in the keyword 'Macedonia' for Serbia, Russia, Italy, Great Britain, France, Netherlands and Sweden is used; additionally, for Bulgaria, Turkey, and Germany, 'History' is a keyword.

The keywords used for Serbia are 'Nature' and 'Adventure,' and 'Ohrid;' for Bulgaria, 'Nature' and 'Adventure;' for Turkey, 'Nature' and 'Adventure;' for Russia, 'Nature' and 'Adventure' (snowboarding); for Great Britain, 'Nature, 'Adventure, and 'Skopje;' for France, 'Food,' 'Wine,' and 'Skopje;' for the Netherlands, 'Tradition' and 'Culture;' for Italy, Germany, and Sweden, the general keyword 'Macedonia' is used.

Table 2 shows the funds spent for online promotion for the period from 16 March to 18 August 2015. The highest numbers of clicks and view are from Serbia, Turkey, Bulgaria, and Russia; the most impressions are from Turkey and then from Russia, Serbia, and Bulgaria. The highest costs for promotion are in UK, Turkey, and Russia.

\section{Results of Survey}

During the international tourism fairs in Sofia, Bulgaria from 11-13 February 2016 and in Belgrade, Serbia from 18-21 February 2016, with the target survey group of visitors at the fairs, interviews were conducted with 144 respondents, 58 in Sofia and 86 in Belgrade. 
Table 2 Funds Spent per Country (16 March to 18 August 2015)

\begin{tabular}{lrrrr}
\hline Country & Clicks/Views & Cost $(\$)$ & Average CPC $(€)$ & Impressions \\
\hline United Kingdom & 373,232 & $28,944.41$ & 0.08 & $3,039,360$ \\
Turkey & $1,214,101$ & $28,799.97$ & 0.02 & $21,546,893$ \\
Russia & $1,015,724$ & $27,754.15$ & 0.03 & $11,135,632$ \\
France & 490,089 & $24,951.09$ & 0.05 & $3,235,907$ \\
Germany & 262,647 & $23,724.76$ & 0.09 & $2,479,649$ \\
Italy & 454,175 & $23,460.06$ & 0.05 & $3,051,442$ \\
Netherlands & 365,276 & $22,298.98$ & 0.06 & $2,063,318$ \\
Bulgaria & $1,125,311$ & $22,227.52$ & 0.02 & $5,626,159$ \\
Serbia & $1,364,210$ & $22,074.56$ & 0.02 & $6,893,137$ \\
Sweden & 204,535 & $16,949.36$ & 0.08 & $1,749,418$ \\
Spain & 36,408 & 676.31 & 0.02 & 723,993 \\
\hline
\end{tabular}

Notes Adapted from Temelkovski (2016).

I chose to do research at this international tourism fairs because the visitors from these countries are among top five visitors of Macedonia for every year, recently. Furthermore, these countries are neighbours to Macedonia, and they offer similar tourism products, such as religious tourism, ski tourism, gastronomy tourism, mountain tourism, and others.

The Belgrade Tourism Fair is the largest tourism event in Serbia and Southeast Europe. It has been meeting global business standards for more than three decades, creating partnership relations with the exhibitors and attracting an increasing number of visitors annually (see http://beogradskisajamturizma.rs). Since 2003, it has been a member of the European Tourism Trade Fairs Association (Eт TFA). Its high quality led it to become a member of another prestigious organization: the International Tourism Trade Fairs Association (I T T FA).

The international Tourist Fair 'Holiday \& Spa Expo' (see http://holidayfair-sofia.com) has been one of the most significant events in the tourism business for over three decades in Bulgaria, providing excellent opportunities for useful business contacts between exhibitors, promoting various products, programs and offers to professionals and the general public.

The survey was conducted through a simple random sample with structured questionnaire by means of a random selection. The questionnaire contains questions of multiple-choice, scale, and checkbox; the responses will assist in the realization of the aim of the survey.

Results from this research have shown that $59 \%$ of the respondents are female and $41 \%$ are male. Regarding the age of the respondents, those of 26 to 35 years represented $27.1 \%, 26.4 \%$ are at age above 55 years, $17.4 \%$ are of age of 36 to 45 years, $15.3 \%$ are of age of 46 to 55 years, and $13.9 \%$ are of age of 15 to 25 years. According to the education, the biggest part even $70.8 \%$ of respondents had university education; $26.4 \%$ had secondary education, and $2.8 \%$ have primary education. According to the social status of respondents, $63.9 \%$ are employed, $18.8 \%$ are retirees, $10.4 \%$ are students and 6.9\% are unemployed. Regarding how much are their annual personal expenses are for tourism and leisure, almost half part of respondents (47.2\%) answered between $€ 500-1500,35.4 \%$ less than $€ 500$, $14.6 \%$ between $€ 1501-2500$, and $2.8 \%$ over $€ 2500$.

In Figure 1 it can be seen that $64 \%$ of respondents had been to Macedonia and $36 \%$ had never been there. From those respondents who never been in Macedonia, $86.5 \%$ answered that they would visit there and $13.5 \%$ that they would not. From those respondents who would not visit Macedonia, $42.9 \%$ answered that they would visit Greece, $28.6 \%$ that they would visit Turkey, and $28.6 \%$ that they would visit some other destinations. 


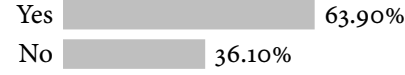

Figure 1 Have You Ever Been in Macedonia?

\begin{tabular}{|c|c|}
\hline \multicolumn{2}{|l|}{ Yes } \\
\hline No & $36.10 \%$ \\
\hline TV & $49.30 \%$ \\
\hline Internet & $43.10 \%$ \\
\hline \multicolumn{2}{|c|}{ Printed editions | $1.40 \%$} \\
\hline \multicolumn{2}{|c|}{ Radio $1.40 \%$} \\
\hline Billboards & $6.90 \%$ \\
\hline Flyers etc. & $7.60 \%$ \\
\hline Tourism fair & $14.60 \%$ \\
\hline I have not seen & $24.30 \%$ \\
\hline
\end{tabular}

Figure 2 Where Have You Seen Advertising of Macedonia as Tourist Destination?

Figure 2 whether respondents had seen advertising about Macedonia as a tourist destination in the previous year and in which medium.

Most of the respondents $49.3 \%$ had seen advertising of Macedonia as a tourist destination on television and $43.1 \%$ had seen on the Internet and social media. Furthermore, $24.3 \%$ of the respondents had not seen any such advertising. Then $14.6 \%$ of the respondents had seen advertising at tourism fair, $7.6 \%$ of the respondents had seen in flyers, catalogues and brochures, $6.9 \%$ of the respondents had seen on billboards, $1.4 \%$ of the respondents had listen advertising on radio and $1.4 \%$ of the respondents had seen in printed editions.

About the impressions of advertising of Macedonia as a tourist destination, $56 . \%$ of respondents said that the advertising was interesting, $17.4 \%$ said that it was exciting, $0.6 \%$ said that it was dull, and $27.7 \%$ of respondents had not seen the advertising.

About information regarding tourist services in Macedonia, $57.6 \%$ of respondents can find enough information, $14.6 \%$ cannot find enough complete information, $15.3 \%$ find insufficient information, and $12.5 \%$ had not searched for such information.

For over half $(54.2 \%)$ of the respondents, the first thing when they think about Macedonia as a tourist destination is Lake Ohrid; $17.4 \%$ of respondents think it is a land of natural beauty, $16 \%$ a land of tradition and

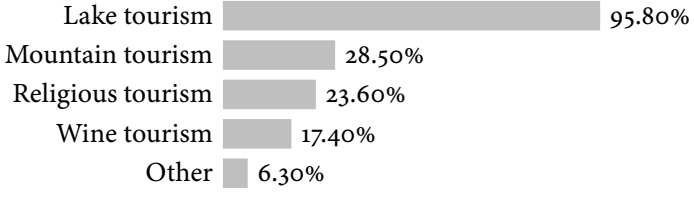

Figure 3 Type of Tourism Product in Macedonia

history; $9.7 \%$ of respondents think of delicious food and wine, $1.4 \%$ the cradle of civilization, while $1.4 \%$ of respondents thing of some other things.

Figure 3 shows that $95.8 \%$ of respondents knows that lake tourism is offered in Macedonia; 28.5\% know that mountain tourism is offered there; $23.6 \%$ of respondents knows about religious tourism there; $17.4 \%$ know about wine tourism, and $6.3 \%$ of respondents knows that some others type of tourism products are offered in Macedonia.

On a scale from 1 (dislike) to 5 (like), the respondents evaluated the promotional materials and the national stand of Macedonia at the international tourism fairs. Half (51.4\%) of respondents gave Grade 5, 38.2\% of respondents gave Grade 4, and $10.4 \%$ of respondents gave Grade 3.

\section{Interview}

The interview was conducted with Ljupco Janevski, Head of Unit for Analysis, Research and Strategic planning, Department for Promotion and Exhibitions, the Agency for the Promotion and Support of Tourism at the international tourism fair in Sofia, Bulgaria.

He said that the agency presents Macedonia as a brand and a tourist destination, and provides an even presentation of all the possibilities for tourism and development of tourism in the country, from a mass tourism to the most specific forms of tourism. This year religious tourism is promoted through brochures and the first guided tours of monasteries; 31 monasteries are offering accommodation in Macedonia. At all fairs in which the agency participates, the offer of tourism in Macedonia is the same.

The greatest interest for tourism in Macedonia is predominantly seen at regional fairs in Turkey, Serbia, Bulgaria and Slovenia. At the tourism fairs in these countries we expect various target groups, because the 
interest for Macedonia as a tourist destination is high. Macedonia is undiscovered destination as for Balkan countries as well as for other countries. Macedonia and these countries have similarity in mental and social aspects and because of that enables faster fluctuation of tourists from these countries and tourists from these countries are in top 10 countries of international tourist arrivals in Macedonia. Also most of macedonian tourists are traveling in these countries.

After each tourist fair, visitors contact us and we have feedback, it's very important that the fan page of Macedonia Timeless on Facebook currently has around 36,000 people[likes], and most interest arises from the natural beauties of Macedonia with more than 1000 likes on certain videos from the campaign Explore Macedonia; we have increased visit at the website of www.tourismmacedonia.gov.mk.

The Agency for the Promotion and Support of Tourism regularly participates in certain B 2 B fairs, such as in London, Brussels, the Netherlands and Rimini, Italy, where there have been great successes. Such a method enables stronger relationships with the tourism sector in Macedonia and in the countries where they are present.

\section{Conclusion}

According to the analysed data, it can be concluded that in the recent years Macedonia has made sustainable efforts for promotion of tourism and from year to year invests significant financial assets for promotion and development of tourism. The tourism products of Macedonia are promoted by the Agency for the Promotion and Support of Tourism through the all available promotional assets as marketing campaign in print media, $\mathrm{TV}$, internet, tourism fairs, billboard campaign, subsidiary and many more activates

Tourism fairs are one of the oldest form of presentation and most important promotional tool of the tourism product and destination. The Agency for Promotion and Support of Tourism every year from annual programs allocating funds for participation in tourism fairs and participated at the most important tourism fairs in Europe and the world.

Positive results of the Macedonian tourist policy are a result of the increased investments in the last five to six years, and making strategies, programs, future plans and objectives for the improvement, development and promotion of tourism.

The first hypothesis, which stated: 'The biggest part of respondents saw the advertising of Macedonia as a tourist destination on the Internet,' can be partially accepted because $50 \%$ of respondents saw the advertising on the $\mathrm{TV}$ and $43 \%$ of respondents advertising on the Internet.

The second hypothesis, which stated: 'The biggest part of respondents know that in Macedonia is offered lake tourism as a type of tourism and the first synonym of Macedonia as a tourist destination is Lake Ohrid, can be accepted in whole because the large majority respondents said that they know that Macedonia offers lake tourism and for more than half of the respondents as the first association for Macedonia as a tourist destination is Lake Ohrid.

This research has been funded and supported from the European Commission. This publication reflects the views only of the author, and the Commission cannot be held responsible for any use which may be made of the information contained therein.

\section{References}

Bhatia, A. K. (2007). The business of tourism: Concepts and strategies. New Delhi, India: Sterling.

Dokumentaren film za Makedonija. (2011, 7 March). Večer. Retrieved from http://vecer.mk/kultura/dokumentaren -film-za-makedonija

Esombia, S. (2013). Global tourism and the environment: The necessities for clean energy and clean transportation usages. Raleigh, NC: Lulu Press.

Macedonia timeless. (2017). In Wikipedia. Retrieved from https://en.wikipedia.org/wiki/Macedonia_Timeless

Temelkovski, O. (2016). Online campaign Macedonia. Retrieved from https://prezi.com/vhchmopifwz6/online -campaign-macedonia/

Travel Channel: Macedonia an exciting destination. (2010, 24 July). Macedonia Online. Retrieved from http:// macedoniaonline.eu/content/view/16114/2/

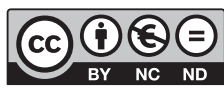

This paper is published under the terms of the Attribution- NonCommercial-NoDerivatives 4.0 International (CC B Y-NC-ND 4.0) License. 